\title{
A FIELD EXPERIMENT CONCERNING CAPILLARY RISE OF MOISTURE IN A HEAVY CLAY SOIL ${ }^{1}$ )
}

\author{
G. P. WIND \\ Central Institute of Agricultural Research, Wageningen
}

\begin{abstract}
SUMMARY
The rate of capillary rise of moisture in a heavy clay soil was calculated by means of a water balance. This moisture movement was found to supply about $150 \mathrm{~mm}$ in 1953. Under favourable circumstances a delivery of 3 to $4 \mathrm{~mm}$ per day is possible. The calculated values appeared to be in conformity with the law of unsaturated moisture flow. A graph was compiled which gives the relation between height above the water-table, $\mathrm{pF}$ and capillary rise.
\end{abstract}

\section{InTRODUCTION}

In the Netherlands there are some regions of heavy river clay soil, agricultural production from which is small compared with the average for this country. These "basin clay soils" (EDELman, 1950) cover a total area of about $60,000 \mathrm{ha}$, the greater part of which is permanent grassland. Plans have been made to improve the soils in question, and the problem now arises: what is the best depth for the water-table?

At present there are two opinions on this question. Visser (1949) considers that a deep water-table is best. In that case, he says, aeration of the soil is better, and deeper root growth is possible. The large soil block which is then rooted contains enough water to enable the land to get through a dry period without grass yield being adversely affected. On the other hand, Pons (1949) states that in two very dry years grassland with high water-tables was found to remain green while grass on soils with low water-tables withered. MinderHOUD (1953) found a negative correlation between the depth of the water-table and the summer yield of grassland on basin clay soils. He also found, from gypsum block observations, that the higher the water-table, the moister was the soil $10 \mathrm{~cm}$ below the surface.

It is not likely that evapotranspiration from moist soils is less than from dry soils, so it is probable that the soils with a high water-table get an extra supply of water from capillary rise.

\section{Experimental procedure}

An experiment was carried out on a basin clay soil near Zaltbommel, between the rivers Waal and Maas. The soil consists of $60 \%$ clay and $40 \%$ silt. Fig. 1 shows the moisture characteristics of this soil. The water-table in summer is about $45 \mathrm{~cm}$ below the surface. In one plot, capillary rise was made impossible by introducing an impervious layer of plastic cloth at a depth of $30 \mathrm{~cm}$. The plastic layer was inserted without disturbing the soil, by drawing a wedge horizontally through the soil. The plastic cloth was on a roll inside the wedge,

1) Received for publication July 28th 1954. 


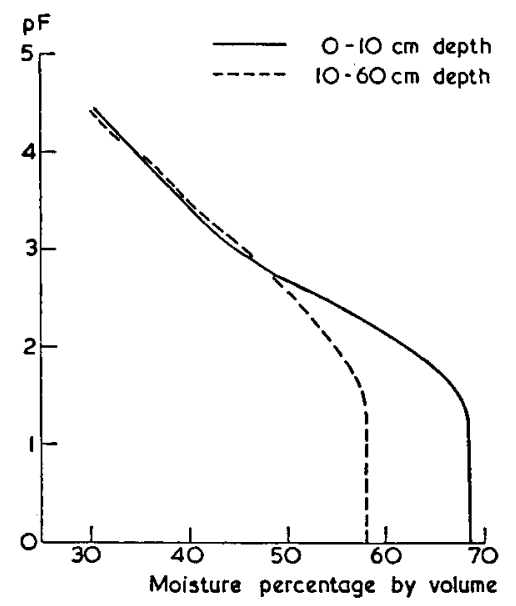

Fig. 1. The pF curves of the soll on Which the experiment was made.

which had a maximum height of $4 \mathrm{~cm}$. As the wedge advanced, the plastic unrolled and remained in the soil.

The plastic cloth was $4 \mathrm{~m}$ long and $1.25 \mathrm{~m}$ broad. In addition, the sides of the soil block were provided with a plastic wall, so that the water could not enter there either.

Soil moisture content and moisture tension were measured with gypsum blocks and nylon units, according to the method of Bouyoucos (1940, 1948). The soil moisture units were installed at depths of $2,5,8,12,18,22$ and $28 \mathrm{~cm}$. In all, 28 units were above the plastic layer.

In the untreated soil 32 moisture units were placed at the depths mentioned above, and also at depths of $32,38,45$ and $55 \mathrm{~cm}$. The resistances measured were converted into terms of $20^{\circ} \mathrm{C}$ with the aid of temperatures read from Philips thermistors.

The experiment started on 24th April, 1953, with introduction of the plastic layer and the moisture units. The first reading of the units took place on 28th April. From then until 14th October, 1953, the moisture units were measured 21 times, at irregular intervals.

\section{EXPERIMENTAL RESULTS}

The soil above the impervious plastic layer, henceforth called the treated plot, became much dryer than the untreated soil. In every dry period, the soil moisture in the treated plot showed a very rapid decrease as compared with that in the untreated soil.

Fig. 2 shows the soil moisture content in the layer $0-30 \mathrm{~cm}$, in both soils.

In this diagram, the dry period in the first 20 days of May is especially interesting. During this period there were practically no losses of soil moisture in the untreated soil. In the same time the treated plot lost practically all 'its available moisture. The moisture content of the $30-60 \mathrm{~cm}$ layer remained constant, so the amount of capillary moisture supplied was nearly' equál to the amount lost by evapotranspiration. In later periods there were fluctuations in the moisture content of the untreated soil, but they were "not" so 


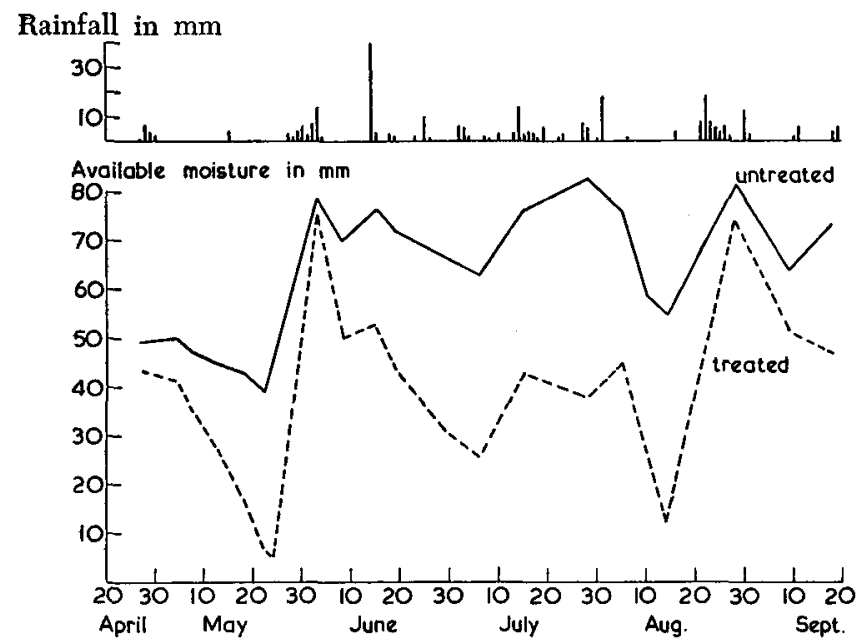

Fig. 2. Available moisture content IN the UPPer $30 \mathrm{CM}$ OF THE tReated plot and THE UNTREATED SOIL DURING THE SUMMER OF 1953. The dotted line represents soil moisture in the treated plot, the continuous line that in the untreated soil. At the top, the rainfall.

great as those in the treated plot. Nevertheless, there was always more moisture in the untreated soil than in the treated plot, which meant that a considerable amount of moisture had been supplied by capillary rise in this soil.

\section{Quantitative Calculation of CAPILLARY Rise of MOISTURE}

For a soil block, we can form an equation for the water-balance:

$$
C+R+M_{1}=M_{2}+E+D \text {. }
$$

In this equation $C$ is the capillary rise of moisture through the bottom of the block. $R$ is the rain, $M_{1}$ and $M_{2}$ the moisture content at the beginning and at the end of the period concerned. $E$ is the evapotranspiration, and $D$ is the downward water movement, called drainage.

$R$ and $M$ are measured. So there remain three unknown factors. If only periods with little rain are concerned, we can assume that $D=0$. For the treated plot, $C=0$ too. So we can calculate the evaporation of this plot, $E_{\mathrm{t}}$. But $E_{\mathrm{t}}$ is not a good estimate of the untreated soil's evapotranspiration $E_{\mathrm{u}}$, because the plot with the plastic layer is much dryer than the untreated soil.

Another estimate of the evapotranspiration has been provided by the lysimeter installation of the Central Institute of Agriculutural Research (MAKKINK, 1953) in Wageningen, at a distance of $30 \mathrm{~km}$ from the venue of the experiment. Mr. MakKINK kindly gave us the evapotranspiration data from 5 lysimeters, in which moisture tension remains constant at a very low value, the potential evapotranspiration $E_{\mathrm{p}}$. These data are higher than the $E_{\mathrm{t}}$ values, but they are probably higher than $E_{\mathrm{u}}$ too.

We can calculate $E_{\mathrm{u}}$ when we know the relation between evapotranspiration and $\mathrm{pF}$, which relation can be determined by dividing $E_{\mathrm{t}}$ by the potential evapotranspiration $E_{\mathrm{p}}$. In Fig. 3 this quotient, the relative evapotranspiration $E_{r}$, is shown in its relation to $\mathrm{pF}$.

By means of the $\mathrm{pF}$ of the upper $10 \mathrm{~cm}$ of the untreated soil, the curve 62 


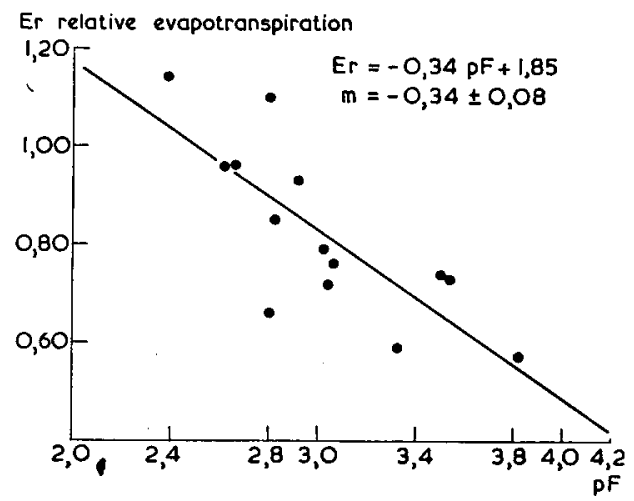

Fig. 3. The Relation BETWEen the RElative eVApotranspiration, and the pF in the UPPER $10 \mathrm{CM}$ OF SOIL, IN THE PLOT WITH THE PLASTIC LAYER.

$E_{\mathrm{r}}=-0.34 \mathrm{pF}+1.85$ of Fig. 3, and the potential evapotranspiration, we now can calculate the untreated soil's evapotranspiration $E_{\mathrm{u}}$.

If we consider only periods without drainage, we can write eq. (1) in the following form :

$$
C=E+M_{2}-M_{1}-R \text {. }
$$

All terms in the right member of the equation are known. So we can calculate capillary rise in the periods without drainage. Altogether, $153 \mathrm{~mm}$ of water rose in the 14 periods, which had a total length of 98 days. There were 4 periods in which capillary rise exceeded $2.0 \mathrm{~mm}$ per day; in one of them the rise was $3.4 \mathrm{~mm}$ per day.

Table 1 gives the amounts of capillary rise, calculated according to eq. (2).

Table 1. Calculation from the experimental data of capillary rise in the 14 periods without drainage.

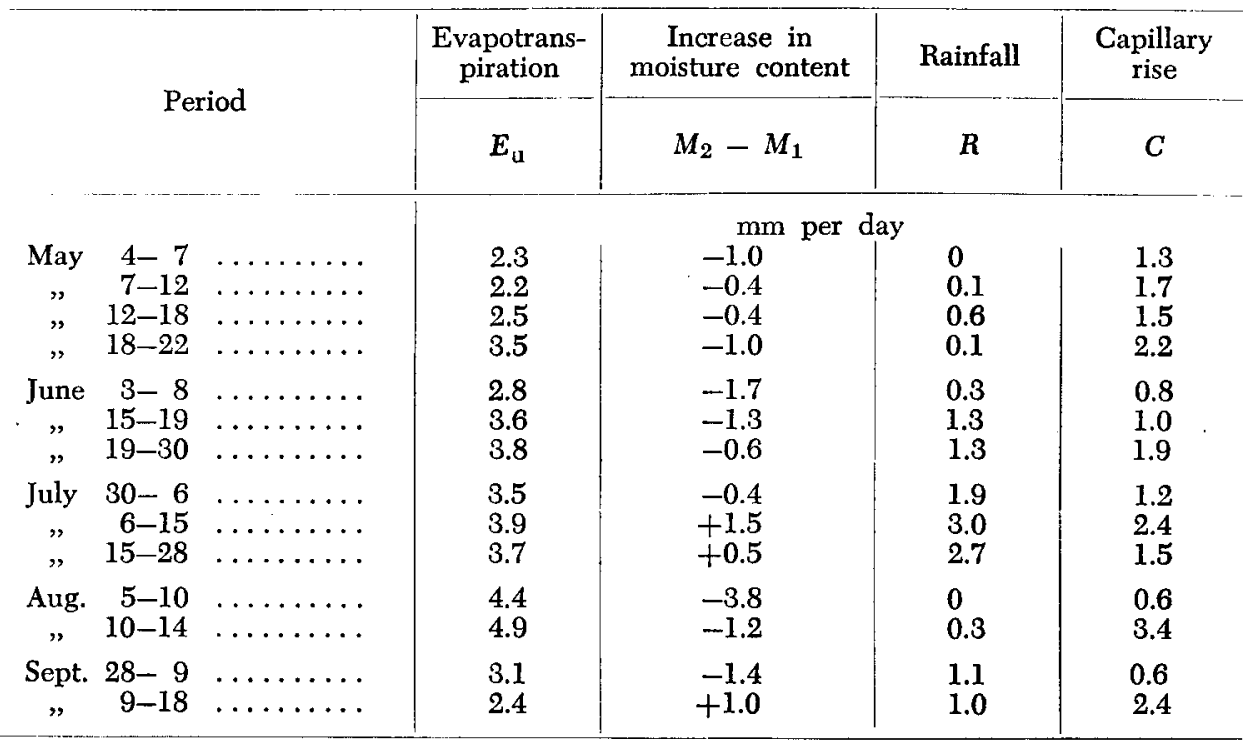




\section{Discussion}

If these amounts are not the result of experimental errors in calculating rainfall, evapotranspiration, etc., but are indeed true measurements of water movements caused by capillary forces, they must be in conformity with the theoretical laws for unsaturated flow.

The equation for the velocity of unsaturated flow is :

$$
v=\lambda \frac{\mathrm{d} \Theta}{\mathrm{d} h}
$$

In this equation $\frac{\mathrm{d} \Theta}{\mathrm{d} h}$ is the potential gradient in the direction of flow, and $\lambda$ is the coefficient of capillary conductivity. The potential $\Theta$ is composed of the capillary potential $\psi$ and the potential due to gravity $h$, if we consider a vertical flow.

So for capillary rise the equation is

$$
v=\lambda \frac{\mathrm{d}(\psi-h)}{\mathrm{d} h}=\lambda\left(\frac{\mathrm{d} \psi}{\mathrm{d} h}-1\right)
$$

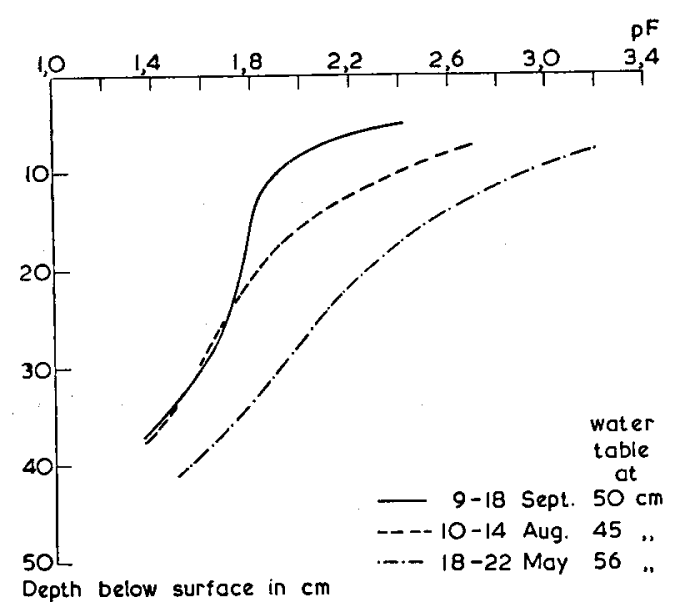

Fig. 4. The capillary potental. (pF) at different depths in the Untreated field, in THREE PERIODS.

The tangents to the curves of Fig. 4 give us $\frac{\mathrm{d} \log \psi}{\mathrm{d} h}$ at any depth we wish. From these values we can calculate $\left(\frac{\mathrm{d} \psi}{\mathrm{d} h}-1\right)$ in the following manner:

$$
\frac{\mathrm{d} \psi}{\mathrm{d} h}-1=2.3 \psi \frac{\mathrm{d} \log \psi}{\mathrm{d} h}-1
$$

Equation (4) is now written :

$$
v=\lambda\left(2.3 \psi \frac{\mathrm{d} \log \psi}{\mathrm{d} h}-1\right)
$$

Before we calculate $\lambda$, two points must be mentioned. Firstly, $v$ is not the same for all depths. For $v$ is the sum of the capillary rise from the ground water $c$ and the moisture $m$ extracted in unit time below the depth concerned. 
So we must write :

$$
c+m=\lambda\left(2.3 \psi \frac{\mathrm{d} \log \psi}{\mathrm{d} h}-1\right)
$$

The second point is that moisture does not flow only through the soil, but through the grass roots too. This movement is independent of the potential gradient in the soil. If we assume that all water transport takes place via the soil, we shall find too high values for the capillary conductivity $\lambda$. Owing to the fact that the quantity of roots is greater at shallower depths, it can be expected that the values of $\lambda$ at different depths will not agree with each other. In cases in which they do agree, it is likely that no active roots are present.

Table 2 gives an example of the method of calculation.

Table 2. Calculation of capillary conductivity from the data of period no. 4, between the 18th and 22nd of May, 1953.

\begin{tabular}{c|c|c|c|c|c|c}
\hline $\begin{array}{c}\text { Depth in } \\
\text { cm below } \\
\text { surface }\end{array}$ & $\begin{array}{c}\mathrm{pF} \\
\log \psi\end{array}$ & $\begin{array}{c}\psi \\
\mathrm{cm}\end{array}$ & $\begin{array}{c}\mathrm{d} \log \psi \\
\mathrm{d} h\end{array}$ & $\left(\begin{array}{c}\mathrm{d} \psi \\
\mathrm{d} h\end{array}\right.$ & $\begin{array}{c}c+m \\
\mathrm{~mm} / \mathrm{day}\end{array}$ & $\begin{array}{c}\lambda \\
\mathrm{mm} / \mathrm{day}\end{array}$ \\
\hline 10 & 2.89 & 780 & 0.088 & 157.0 & 2.6 & 0.017 \\
15 & 2.51 & 320 & 0.061 & 43.0 & 2.2 & 0.051 \\
20 & 2.27 & 186 & 0.035 & 13.7 & 2.2 & 0.16 \\
25 & 2.10 & 126 & 0.036 & 9.1 & 2.2 & 0.24 \\
30 & 1.91 & 81 & 0.037 & 5.8 & 2.2 & 0.38 \\
\hline
\end{tabular}

The results of similar calculations for the 14 periods without drainage, and at the 5 depths mentioned in Table 2, are given in Fig. 5. It appears, in accordance with the results of Richands (1952) and others, that capillary conductivity is not a single value. The data are dependent on the soil moisture tension; so we show them in their relation to $\mathrm{pF}$.

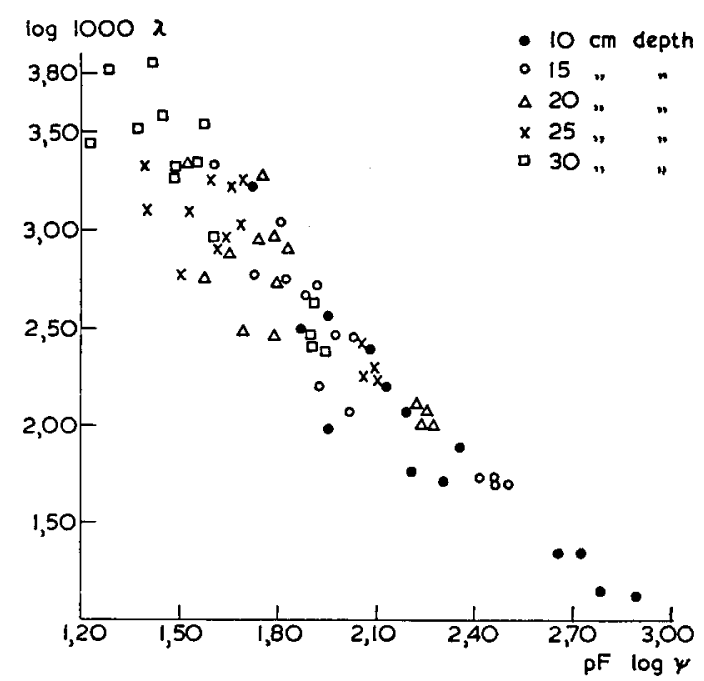

Fig. 5. The calculated conductivity datä plotted against pF.

In this figure we see that a very close degree of agreement exists between 
the data of the 5 depths. We must therefore conclude that at these depths practically all movement of water is via the soil, and that only very little water is transported by the roots. At depths of less than $10 \mathrm{~cm}$ the calculated values of $\lambda$ deviated strongly from the other values. It is most likely that at these depths the flow of water through the roots becomes important. Obviously there are no water-absorbing roots at depths below $10 \mathrm{~cm}$.

Fig. 5 provides proof that the quantities of water calculated as resulting from capillary rise are indeed due to capillary water movements. They were not the result of errors in the experimental data. For in that case such a close relation between capillary conductivity and capillary potential would not be found to exist.

As will be seen from Fig. 6, the capillary conductivity of this soil is very low.

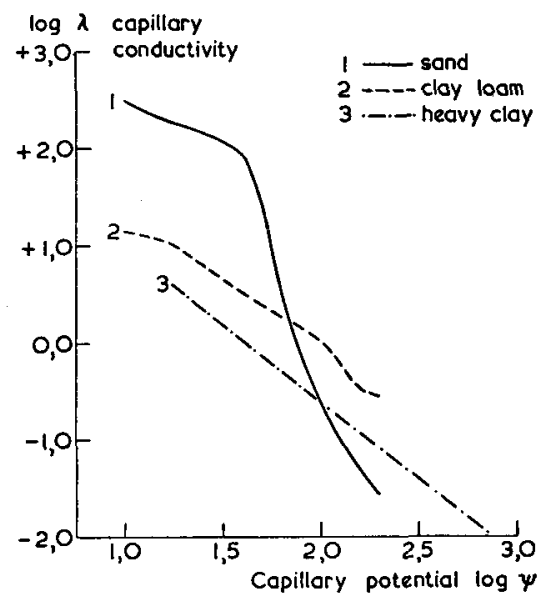

Fig. 6. Comparison of conductivity Data from Richards and Moore (SAND AND Clay LOAM) WITH THE RESULTS OF OUR EXPERIMENT (HEAVY CLAY).

Our data for heavy clay are compared here with two curves plotted by Richards and MoOrE (1952) for clay loam and sand. In wet condition, the conductivity of sand is about 100 times as high as that of the heavy clay. Above $\mathrm{pF} 2.0$ the conductivity of heavy clay is greater. The clay loam curve is nearly parallel with ours, but it lies 3 times as high. Nevertheless, in spite of this low conductivity, an appreciable amount of water can rise capillarily.

\section{Practical application}

It is possible now, on the basis of this new knowledge of capillary moisture rise, to answer the question about the best summer depth of the water-table for this soil. The stipulation we make is that the $\mathrm{pF}$ at the bottom of the root zone is not allowed to exceed a certain value. That means that in dry periods capillary rise must be able to compensate for water lost by evapotranspiration.

We shall now calculate the relation of the $\mathrm{pF}$ at $10 \mathrm{~cm}$ depth to the depth of the water-table.

If we adjust the points of Fig. 5 we get the following formula :

$$
\log 1000 \lambda=-1.57 \log \psi+5.54 \text {. }
$$


The mean errors are 0.10 and 0.34 respectively.

We can write this equation as :

$$
\lambda=b \psi^{-a}
$$

$$
a=1.57 \pm 0.10 \quad \log b=2.54 \pm 0.34
$$

For the sake of simplicity we make $a=1.50$ (the mean error of $a$ allows that), but $b$ then has to be altered too; otherwise the line would no longer pass through the points.

Thus, $\log b=2.40 \longrightarrow b=250$.

From equations (4) and (8) we form

$$
v=b \psi^{-a}\left(\frac{\mathrm{d} \psi}{\mathrm{d} h}-1\right)
$$

We may change $v$ into $c$ because when capillary rise equals evapotranspiration, no water is extracted from the soil.

$$
\begin{gathered}
\frac{\mathrm{d} \psi}{\mathrm{d} h}={ }_{b}^{c} \psi^{a}+1 \\
h=\int \frac{\mathrm{d} \psi}{\frac{c}{b} \psi^{a}+1}
\end{gathered}
$$

If $a$ were 1 or 2 , this form could be elementarily integrated. We now introduce : $\mathrm{y}^{2}=\psi$; then $\mathrm{d} \psi=2 \mathrm{y}$ dy. Instead of equation (10) we now write :

$$
h=\int \frac{2 \mathrm{y} \mathrm{dy}}{c} \frac{\mathrm{y}^{3}+1}{b}
$$

The solution of equation (11) is :

$\left.h=\frac{2}{3}\left(\frac{b}{c}\right)^{\frac{2}{3}} \mid \frac{1}{2} \ln \left(x^{2}-\mathrm{x}+1\right)+\sqrt{3} \operatorname{arc} \tan \frac{2 x-1}{\sqrt{3}}-\ln (x+1)+\mathrm{K}\right\}$

In this $\mathrm{x}=\left(\frac{c}{b}\right)^{\frac{1}{3}} \mathrm{y}=\left(\frac{c}{b}\right)^{\frac{1}{3}} \psi^{\frac{1}{2}}$

In the case of the water-table $h=0$ and $\psi=0$

$$
\begin{gathered}
0=\frac{2}{3}\left(\frac{b}{c}\right)^{\frac{2}{3}}\left(0+\sqrt{3} \arctan \frac{-1}{\sqrt{3}}-0+\mathrm{K}\right) \\
\text { So } \quad \mathrm{K}=0.91
\end{gathered}
$$

In Fig. 7 a graph is given for equation 13 when $\mathrm{c}=0,1,2,3$ and $4 \mathrm{~mm}$ per day.

In integrating equation (11) from 0 we are making a mistake by assuming that equation $(8)$ is valid from $\psi=0$. In that case $\lambda$ would be $\sim$. It would be better to assume that equation (8) is valid when $\log \psi>1.20$ (see Figs. 5 and 6 ), and to suppose that $\lambda$ is constant between this value and $\psi=0$. But for the sake of simplicity we integrate from $\psi=0$, because the error involved is very small. 


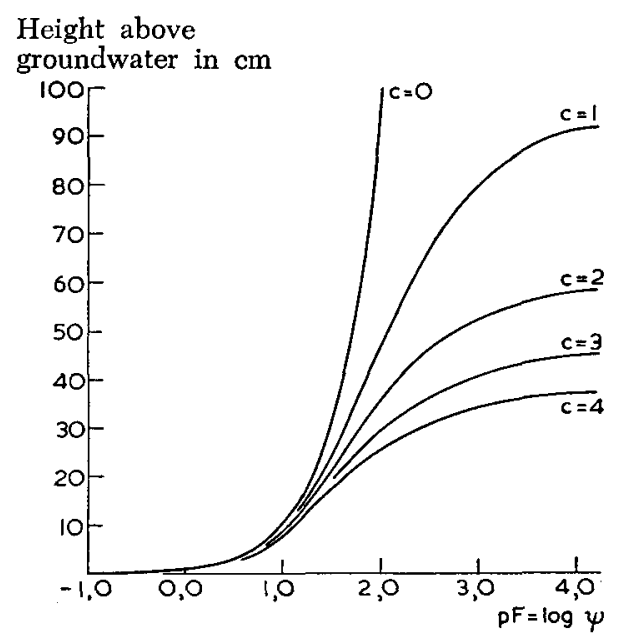

Fig. 7. The Relation BetWeen the height above the Water-table, the pF, and difFERENT RATES OF CAPILLARY RISE.

Owing to this the curves in Fig. 7 are about $1.5 \mathrm{~cm}$ too high.

What, it may be asked, is the purpose of the curves in Fig. 7 ? They are the same as the curves, examples of which were given in Fig. 4. Those curves were differentiated by drawing the tangents to them. The differential ratios, together with the relevant rates of capillary rise, were adjusted. The mean line from this adjustment was then integrated. And this integration yielded a formula in which three independent factors were found, namely, those that occur in Fig. 4 : the height above the water-table, the $\mathrm{pF}$ and the rate of capillary rise of moisture. Fig. 7 gives the relation between those 3 factors.

When there is no capillary movement, the capillary potential (in $\mathrm{cm}$ ) equals the height above the water-table (in $\mathrm{cm}$ ). So for $c=0$ we get:

$$
\mathrm{pF}=\log \psi=\log h \text {. }
$$

When there is a certain capillary rise, there must be a certain potential gradient. The higher the rate of capillary rise the further to the right must the curve go. The soil must therefore be drier. At a height of $40 \mathrm{~cm}$ above the water-table the $\mathrm{pF}$ is 1.85 if capillary rise is $1 \mathrm{~mm}$ per day. When the rise is $3 \mathrm{~mm}$ per day the $\mathrm{pF}$ is 2.85 . At this height, capillary rise cannot be as much as $4 \mathrm{~mm}$ per day, for then the $\mathrm{pF}$ would have to be higher than 7 . But at $30 \mathrm{~cm}$ a capillary rise of $4 \mathrm{~mm}$ per day is possible. At $50 \mathrm{~cm}$ even $3 \mathrm{~mm}$ has ceased to be possible. So the rate of capillary rise is limited by the height above the water-table. That means that Fig. 7 can give us the most desirable depth for the water-table in summer.

In dry periods capillary rise must equal evapotranspiration. If the latter is greater than the former the soil will become drier, the result of which will be firstly, that capillary rise will become greater, and secondly, that evapotranspiration will decrease (see Fig. 3).

If we wish to calculate the most suitable depth for the water-table for this soil we must make two stipulations. We must demand, for instance, that the $\mathrm{pF}$ of the lower limit $(10 \mathrm{~cm})$ of the active root zone shall not exceed 3.0 . That means that the upper $10 \mathrm{~cm}$ of soil will be rather dry.

The second stipulation is that the rate of capillary rise must be $3 \mathrm{~mm}$. 
That amount is not very high, for in dry periods evapotranspiration is about $4 \mathrm{~mm}$ per day.

We now look at the diagram to see the depth at which the curve for $3 \mathrm{~mm}$ crosses the line $\mathrm{pF}=3.0$. That is at $41 \mathrm{~cm}$. So the lower limit of the active root zone must be $41 \mathrm{~cm}$ above the water-table. Since the root zone is $10 \mathrm{~cm}$ thick, the water-table in summer must lie at a depth of $50 \mathrm{~cm}$ or less.

When we allow the $\mathrm{pF}$ to reach higher values, there is only a slight difference in the most suitable depth for the water-table if we remain on the curve $\mathrm{c}=3$. But, as appears from Fig. 3, evapotranspiration decreases if moisture tension increases. So it will not be necessary to maintain a capillary rise of $3 \mathrm{~mm}$ per day. If the $\mathrm{pF}$ is 4.0 , capillary rise must be $\frac{49}{83} \times 3.0 \mathrm{~mm}$ per day, according to Fig. 3, i.e., $1.8 \mathrm{~mm}$. In that case a water-table at a depth of $70 \mathrm{~cm}$ will be sufficient to maintain equilibrium.

\section{Literature}

Bovyoucos, G. J. \& A. H. Mick : An electrical resistance method for the continuous measurement of soil moisture under field conditions. Mich. Agr. Exp. Sta. Tech. Bull. 172 (1940).

- -, - _ : A fabric absorption unit for continuous measurement of soil moisture in the field. Soil Sci. 66 (1948) 217-232.

Edelman, C. H.: Soils of the Netherlands. Amsterdam, 1950.

Makkink, G. F. : Een nieuw lysimeterstation. Water no. 13 (1953) 159-163.

Mrnderhoud, J. W.: Personal communication.

Pons, L. J. : Rapport waterhuishouding van komkleigronden. Internal report 1949.

Richards, L. A. \& D. C. Moore: Influence of capillary conductivity and depth of wetting on moisture retention in soil. Trans. Am. Geophys. Un. 33 (1952) 531-5+0.

Visser, W. C. : De vochthuishouding van komkleigebieden. Internal report 1949. 